anthropology \& materialism

\section{Anthropology \& Materialism}

A Journal of Social Research

$3 \mid 2016$

Utopia: The Elsewhere and The Otherwise

\title{
Guerre et Culture : situation de la philosophie contemporaine
}

War and Culture: situation of the Contemporary Philosophy

Guerra y cultura: situación de la filosofía contemporánea

\section{Stéphane Douailler}

\section{OpenEdition}

Journals

Édition électronique

URL : http://journals.openedition.org/am/661

DOI : 10.4000/am.661

ISSN : 2364-0480

Éditeur :

CETCOPRA, CRASSH - Center for Research in the Arts Social Sciences and Humanities, Fakultät Gestaltung - Universität der Künste Berlin

Référence électronique

Stéphane Douailler, «Guerre et Culture : situation de la philosophie contemporaine », Anthropology \& Materialism [En ligne], 3 | 2016, mis en ligne le 01 décembre 2016, consulté le 30 avril 2019. URL : http://journals.openedition.org/am/661 ; DOI : 10.4000/am.661

Ce document a été généré automatiquement le 30 avril 2019.

Tous droits réservés 


\title{
Guerre et Culture : situation de la philosophie contemporaine
}

\author{
War and Culture: situation of the Contemporary Philosophy \\ Guerra y cultura: situación de la filosofía contemporánea
}

\author{
Stéphane Douailler
}

Les œuvres et manifestations de la culture se tiennent au bord de la déchirure de leur substance, de leurs jours, nuits et ciel, par les orages de la guerre. Cela a été maintes fois souligné. Car ce n'est pas seulement qu'ait manqué d'exister une période historique qui n'aurait pas contraint à traverser des guerres, et que celles-là sembleraient alors ne pas vouloir cesser de gronder ici ou là, loin ou près. Mais c'est aussi que la culture n'a pas la guerre pour décor et contexte plus ou moins aléatoires. La culture, telle que nous la connaissons, a été imprégnée en son cœur par les guerres. Marquée et à chaque instant transformée par elles. C'est un sujet d'études qui n'est pas parvenu à sa conclusion que celui qui observe et examine comment un autre monde, d'autres techniques et institutions, d'autres arts, d'autres sensibilités, sont en réalité sortis de la première guerre mondiale. Le fait est difficile à trancher de savoir si la guerre de 1939-1945 est venue effectivement en tant qu'une deuxième guerre mondiale ou si nous ne sommes pas entrés depuis longtemps dans une guerre qui ne trouve pas son achèvement. Les recherches postcoloniales et les échos qu'aujourd'hui elles suscitent ne cessent de croiser cette première guerre, ou cette guerre inachevable, et d'attester que nous n'en avons pas réellement fini avec elle(s). L'expérience la plus infimement authentique de la culture contemporaine ne peut manquer d'éprouver qu'elle abrite en elle, manifeste, travaille, transforme des forces qui existent sous une forme déchaînée ou autrement mise en œuvre dans des guerres ou dans cette guerre qui n'en finit pas. Cette situation vaut à mes yeux pour la philosophie. Des guerres, et en réalité des guerres innombrables grondent dans le texte de la philosophie. Le trait me paraît extrêmement frappant dans la philosophie et en réalité pour cet espace de pensée, de méthodes et de travaux qu'on cherche aujourd'hui à désigner sous le nom de philosophie française contemporaine. Cet espace retentit encore des guerres mondiales, de cette guerre qui s'est nommée 
révolution, de toutes les guerres de libération coloniale, de cette grande guerre civile dans lequel nous vivons peut-être aujourd'hui. La présence de l'une ou de l'autre de ces guerres dans les œuvres de Derrida, Deleuze, Foucault, Lyotard, Badiou, Rancière, Balibar, Zizeck et tant d'autres, aussi bien que dans les œuvres des autres européens, Benjamin, Adorno, Horkheimer, Habermas et tant d'autres de nouveau, ou encore bien entendu dans le travail philosophique de tant d'autres continents que l'Europe, cette présence est patente. Dans toutes ces œuvres des guerres se déchaînent. S'apaisent. Subissent la transformation des conflits qui les nourrissent. Se muent en paix qui appellent la réflexion. C'est le devenir d'une de ces guerres dans la culture européenne et de ce fait dans les philosophies qu'elle a produites depuis un siècle au moins que je me propose d'évoquer.

2 En 1926 il arriva que des prescripteurs du monde culturel jugèrent bon, une fois de plus, de lancer une «enquête littéraire sur les meilleurs livres de l'année ». À celle-là, ainsi qu'au contexte dans lequel l'idée fut émise, Bertolt Brecht choisit de répondre en allant directement au fond des choses : "Pour le prix d'un disque de chants de Noël on peut acheter à ses enfants ce monstrueux livre d'images qui s'appelle Guerre à la guerre : ce sont des documents photographiques qui montrent un portrait réussi de l'humanité ». Le ton et l'intention, comme Georges Didi-Huberman le souligne au moment de citer cette anecdote dans son livre Quand les images prennent position. L'oeil de l'histoire, sont grinçants. Ils s'efforcent de faire grincer l'idée de culture qui se tient tapie dans cette initiative, manifestant non seulement sa soumission immédiate à la finalité marchande, mais aussi les collisions entre portraits de l'humanité que sa magie ne sait pas dominer jusque dans les moments où elle emprunte à la magie de Noël. La désolante banalité de l'initiative ne faisait que rendre manifeste le besoin de saisir dans la culture d'autres ressorts. De trouver, à la place de la magie marchande et impuissante face à la guerre à laquelle cette culture s'adonne, une culture capable de quelques autres tours. Par exemple, selon une association qu'offre la conclusion d'un article de Walter Benjamin sur les Théories du fascisme allemand. À propos de l'ouvrage collectif Guerre et Guerriers publié sous la direction d'Ernst Jünger, et selon les termes que Walter Benjamin emploie à cette occasion, d'un " tour de prestidigitation marxiste $»^{1}$. Ce qu'il convoque par là est, peut-on supposer, la dialectique en même temps que l'insertion dans des réalités en conflit, c'est-à-dire des gestes de pensée qui font entrer dans un ordre de choses sérieuses. Or, ce qui sur un tel plan se laisse opposer à la guerre s'avère être encore la guerre, ou du moins quelque activité qu'un slogan tel que celui de Guerre à la guerre saisi par B. Brecht dans le livre d'images d'Ernst Friedrich qui porte ce titre ${ }^{2}$ fait pressentir, c'est-à-dire qui lui demeurerait de quelque façon apparentée. La culture qui saurait véritablement réaliser les tours de magie de Noël, celle qui saurait fabriquer un portrait non seulement réussi mais en même temps transformé de l'humanité, serait en ce sens celle qui s'avérerait capable de produire les métamorphoses civiles de ce qui se déchaîne, mal, dans les guerres.

3 À cette situation de la culture par rapport à la guerre, Walter Benjamin ajoute dans Théories $d u$ fascisme allemand un autre trait. La culture que nous connaissons, si nous ne voulons pas nous la rendre obscure en l'appréhendant au regard d'une guerre ou d'une conflictualité "éternelles », « dernières », se rapporte, pour les métamorphoses qu'elles requièrent, à des guerres réelles qui ont été gagnées et perdues. Qui ont fait des vainqueurs et des vaincus. Le rappel en est adressé par Walter Benjamin à Ernst Jünger, aux auteurs du livre collectif Guerre et guerriers, et au déchiffrement qu'ils avaient proposé 
des voies à venir de la culture à partir de l'expérience de la première guerre mondiale en omettant de tenir compte du fait qu'il appartient à une guerre perdue d'échapper au vaincu et de le déposséder «non pas seulement de la guerre prise absolument et en général, mais aussi du moindre de ses épisodes, du plus subtil de ses mouvements, de la plus obscure de ses opérations $»^{3}$. Cette perte d'une expérience que le vaincu a néanmoins faite et acquise est certainement pour Walter Benjamin moins irrémédiable que ne l'énonce ici la critique adressée aux auteurs de l'ouvrage Guerre et guerriers et à leur manière d'affronter ce qui leur est arrivé. La guerre repose aussi entre les mains du vaincu, à la condition de sa métamorphose civile, et donc, comme Walter Benjamin l'exemplifie notamment à propos de Berlin Alexanderplatz d'Alfred Döblin, au prix de quelque « astuce », " grandiose ». Dans Berlin Alexanderplatz Walter Benjamin veut en effet identifier un moment presque insensible de bascule où se retournerait la dépossession que le livre méthodiquement effectue de la faim d'avoir un destin dont le héros est animé. Par un effet d'écriture du roman, ce dernier réussirait à échapper au contrôle que Döblin exerce sur lui, à se libérer de l'exemplarité qui le rive à sa condition de vaincu et l'enferre dans un chemin de sagesse, à se saisir des chances et aléa d'une existence « littéraire ${ }^{4}$ où il apprend à "s'aider lui-même »5. Ce qui a le dernier mot, c'est une culture capable de tels tours de prestidigitation par lesquels de telles métamorphoses s'opèrent. Mais dans ces conditions le rappel vaut sans doute aussi pour ce qui peut s'appeler culture pour nous, qui sommes les vaincus de conflits innombrables, et qui persévérons en eux sans les laisser nous échapper, sans nous en laisser déposséder, en travaillant obstinément à cultiver les forces qu'au prix de leurs métamorphoses ils délivrent.

\section{Photographie et aventures de la pédagogie directive}

4 Tournons nous alors vers Ernst Friedrich et son livre Guerre à la guerre. Co-fondateur dès 1908 d'un Cercle de jeunes travailleurs à Breslau, Ernst Friedrich interrompt à l'âge de 17 ans son apprentissage d'imprimeur pour rejoindre le parti social-démocrate (SPD). On est à ce moment en 1911. Les années qui suivent le voient s'engager dans les actions de la jeunesse ouvrière antimilitariste, participer à des combats de rue et à des actions de sabotage, affronter le pouvoir policier et militaire, subir des condamnations à des travaux de guerre. Ayant déchiré sa carte du parti le jour où le SPD vote les crédits militaires, il rejoint en 1917 la jeunesse socialiste libre de Karl Liebknecht puis devient une tête dirigeante de la jeunesse anarchiste. Il poursuit son combat contre la guerre après 1918, fonde un Centre de jeunesse (Jugendheim) où se retrouvent des jeunes anti-autoritaires et des artistes révolutionnaires unis dans la lutte contre le militarisme. Il est l'un des orateurs du grand rassemblement anti-guerre qui le 31 juillet 1921 rassemble plus de 100 000 manifestants face à la cathédrale de Berlin. En 1925, un an après la publication de Guerre à la guerre, il ouvre au cœur de Berlin et de la Prusse, à cinq minutes de la Préfecture, un musée Anti-guerre (Anti-Kriegs Museum) dont il fait un lieu stratégique d'activités culturelles et politiques. Elles lui valent en 1930 trois ans de prison dont un an ferme pour agitation. Le lieu est saccagé par les SA en 1933 qui y installent leurs propres expositions avant qu'il devienne un centre de torture. Avec les archives qu'il a préventivement réussi à sauver Ernst Friedrich le réouvre en 1936 à Bruxelles, lieu de rencontre de la jeunesse antimilitariste mondiale, mais l'invasion allemande le rattrape et n'oublie pas de procéder à une deuxième destruction du musée. Celui-là est finalement réouvert à Berlin quinze ans après sa mort sous l'égide du WRI (War Resisters 
International), un mouvement qui qualifie la guerre de crime contre l'humanité depuis 1921, et il accueille jusqu'à aujourd'hui des actions artistiques dans une Peace Gallery'.

La fabrication et la publication du livre Guerre à la guerre est, de cette histoire, l'un des moments clés. Livre d'images «monstrueux» selon Bertolt Brecht, il possède incontestablement dans les images : plus de 180 photographies, sa substance même. Un tableau de la guerre s'y dessine - effroyable, on l'aura compris - qui fait pièce à d'autres publications de la même époque, qui, à l'instar d'Ernst Friedrich, auront voulu à cette occasion faire de la prise de vue photographique le moyen privilégié et véridique pour capter la première guerre mondiale en sa réalité historique et vécue. Comme le rappelle une spécialiste de cette histoire, Julia Encke dans son livre Instants du danger. La guerre et les sens (1914-1934)', la première guerre mondiale s'est dès le début employée à sa représentation à travers la constitution d'une archive photographique gigantesque pour laquelle l'état major général allemand, et sa division de la presse chargée tant de la censure que de la transmission d'images de guerre aux journaux, firent appel aux cercles et associations de photographes ainsi qu'à tous les soldats susceptibles d'adresser depuis le front des clichés. Cette documentation, qui privilégia sur les tableaux de groupes ou d'individus - jugés sans intérêt - la photographie d'objets, de lieux, de moments, atteignit 45000 images dès 1915. La collection ne cessa de s'agrandir jusqu'en 1918 avant de faire place à la naissance d'une sorte de genre avec la publication de premiers volumes photographiques. La plupart d'entre eux ${ }^{8}$ se rejoignent dans le projet de lier ensemble et dans un même sort une inspiration nationaliste militariste, et, malgré les montages et les retouches qui furent en réalité nombreux, une authenticité proclamée des documents photographiques cités comme s'ils pouvaient porter témoignage d'une vérité atteinte directement. Ernst Friedrich, qui conservera un souci extrême de cette même archive à laquelle s'adosse le projet de l'Anti-Kriegs Museum, puise lui aussi en elle quand il compose son ouvrage à partir de photographies reproduites dans les journaux (notamment La Freie Welt), et de clichés transmis par des soldats. Mais ce qui distingue surtout son livre est qu'il fit de ces images, quant à lui, la matière d'une réorganisation radicale des modes d'expression formels du discours politique pacifiste et anarchiste, ainsi alors que de ce discours lui-même. Entre les recueils photographiques animés par un nationalisme militariste qui trouvera certainement dans Guerre et guerriers coordonné par Ernst Jünger son expression la plus exacte, et Guerre à la guerre !, il n'y a alors pas seulement la différence d'orientation politique telle qu'elle renvoie à une conflictualité de longue portée à défaut d'être "éternelle» mais il y a aussi un traitement tout autre de la photographie et de ses images, et, à son occasion, dans l'élément de la culture, d'autres puissances politiquement différenciées de conduire une même guerre et une même condition de vaincu vers des métamorphoses civiles.

Dans l'univers civil où il se déploie et s'acquitte de sa tâche, le livre d'Ernst Friedrich rencontre pour sa transformation une pédagogie politique que ceux qui fréquentent quelque peu les fascicules et brochures socialistes, anarchistes et révolutionnaires des derniers siècles peuvent reconnaître en particulier à leur typographie (figure 1). Des alternances de caractères gras et normaux, des changements de polices et de tailles de caractères, des espacements modifiés entre les lettres, des majuscules apparaissant dans le cours du texte et bien d'autres procédés viennent présenter devant le regard une prélecture qui offre mais aussi revendique de faire le travail de sélection, lequel, en différenciant les uns des autres les mots et passages importants, probants, illustratifs, à mémoriser, à comprendre, à élever au rang de principes, à diffuser sous forme de slogans, 
etc., engage et insère d'avance la pensée et l'action dans les opérations différenciées dont elles sont jugées capables. Plus que l'ornementation typographique qui la rend visible c'est en amont cette présélection même, ainsi que l'efficience qu'elle vise, qui dénonce dans la publication et sa forme la présence agissante de la pédagogie explicative ${ }^{9}$, et, à travers ses explications, directive. Jusque dans l'ajustement des typographies du texte à des inflexions orales d'un discours s'assurant de tous ses moyens d'emporter les convictions, cette dernière continue d'habiter et de régir jusqu'à la caricature le manifeste « Aux peuples de toutes les nations » qui ouvre Guerre à la guerre!. Mais elle n'est pas moins absente pour autant des autres recueils photographiques, contemporains du livre d'Ernst Friedrich, y compris des nombreux recueils publiés ou édités par Ernst Jünger : Luftfahrt is Not!, Das Antlitz des Weltkrieges - Fronterlebnisse deutscher Soldaten, Hier spricht der Feind - Kriegserlebnisse unserer Gegner, Die verändete Welt ${ }^{10}$, en ce qu'eux aussi placent leur action dans une sélection qu'ils mettent sous les yeux de leurs lecteurs et qui est celle des images qu'ils choisissent, rapprochent, ordonnent, font témoigner. L'authenticité, la vérité fidèle voire la perception augmentée prêtées à la prise de vue photographique, loin de suspendre la pédagogie directive ou d'ouvrir de nouvelles voies, la renforcent. L'autorité différenciée attribuée dans le texte préliminaire de Guerre à la guerre! aux caractères typographiques renforcés afin de mieux conduire l'esprit du lecteur est strictement reprise en même temps que dépassée dans sa volonté et recherche d'efficacité par l'authenticité attribuée aux prises de vue photographiques dès lors que le lecteur est invité à y ressentir ou pressentir, dans le choc et dans l'effroi, le réel même au moment où ses yeux et son esprit sont en réalité dirigés et pris en main par des documents retouchés et ordonnés par un auteur ou un éditeur assuré de détenir les vérités enseignées par l'expérience du front.

Figure 1

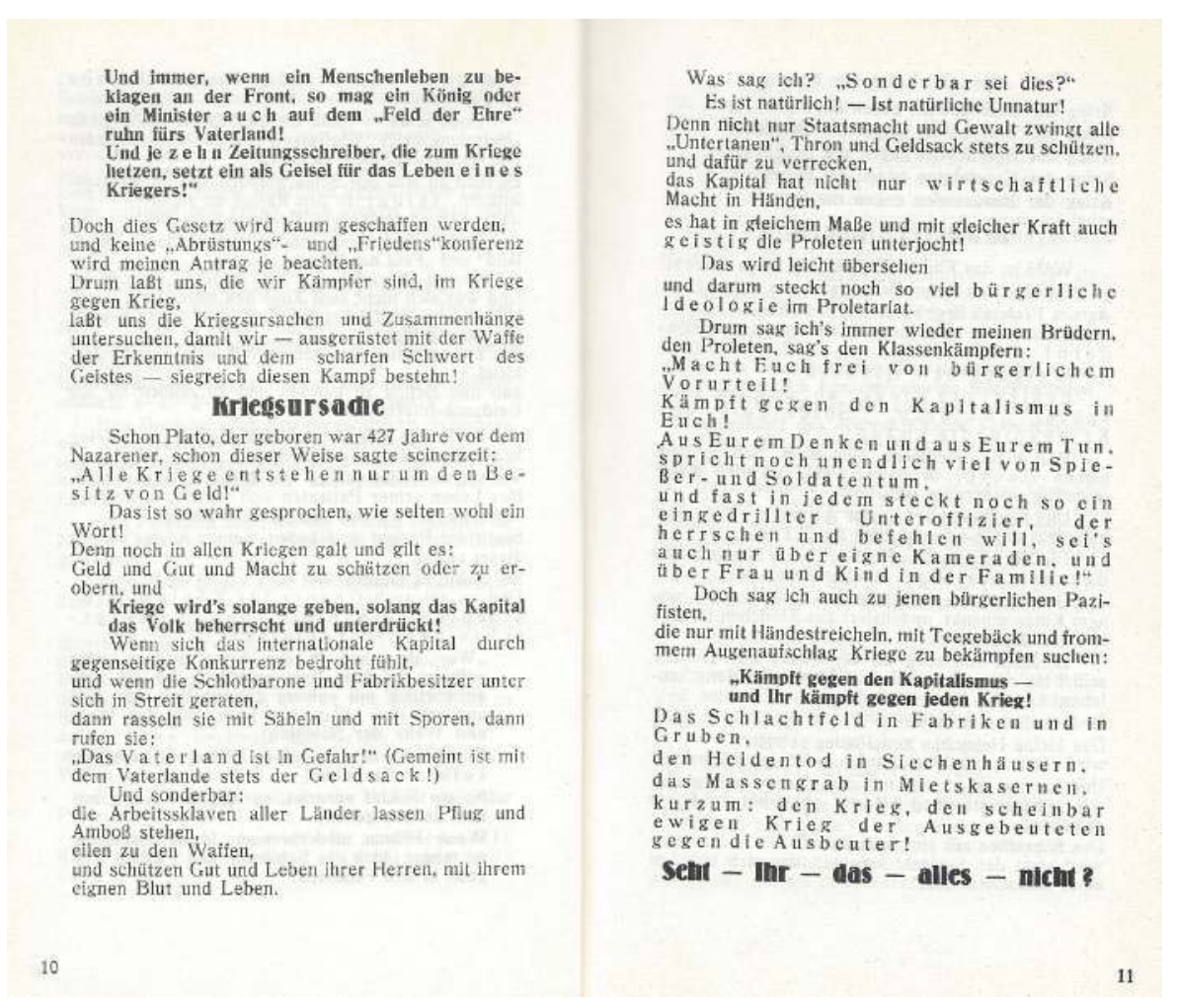

Ernst Friedrich, Krieg dem Kriege! Guerre à la guerre! War against war! Oorlog aan den Oorlog, pp. 10-1 
Figure 2

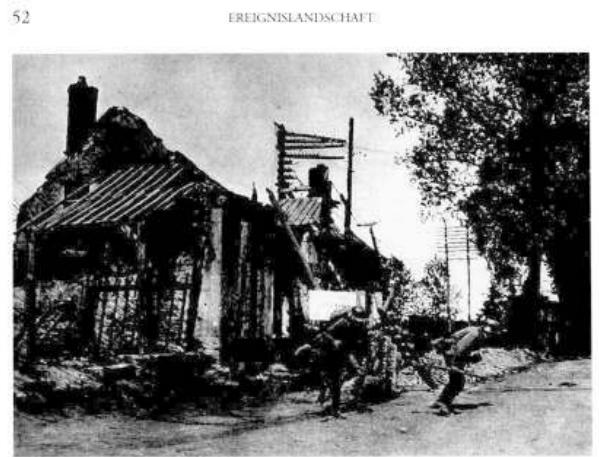

Durch das gessürmte Pont Arcy sich vorarbeitende Infanceric (Abb, 22)

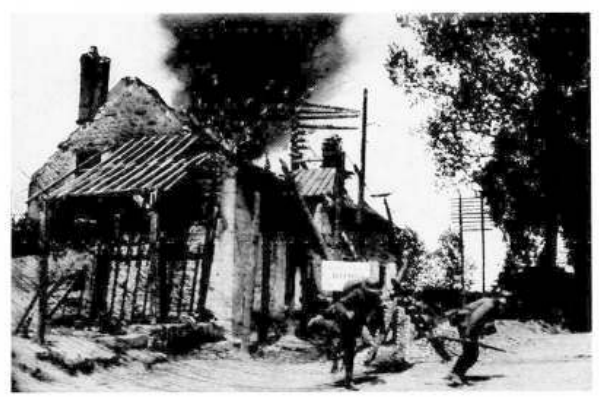

Granareinschlar in ein französisches Dorf (Abb. 23)

Julia Encke, Augenblicke der Gefahr : der Krieg und die Sinne (1914-1934), p. 52

Figure 3

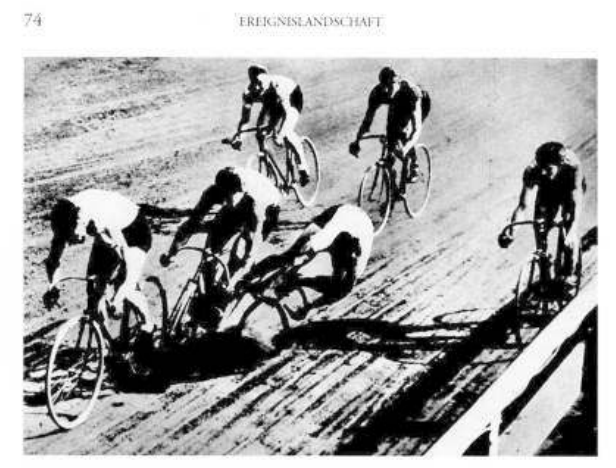

Stur cines Radrennfahrees (Abb, 28)

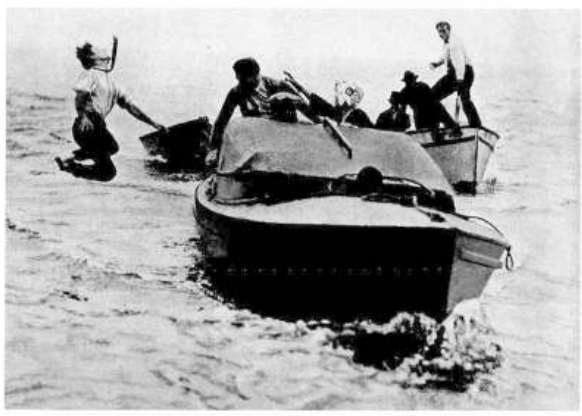

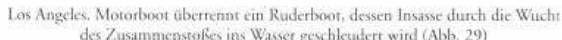

Julia Encke, Augenblicke der Gefahr : der Krieg und die Sinne (1914-1934), p. 74 
Figure 4

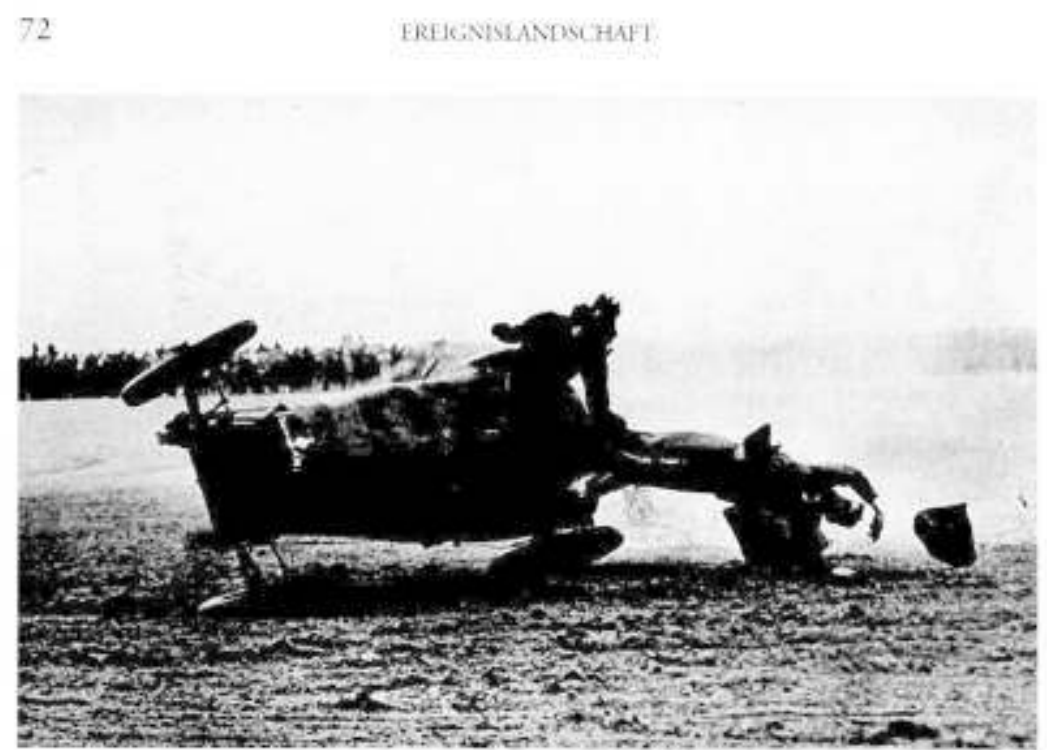

Die lecre Sckunde (Abb, 27)

Figure 5

88

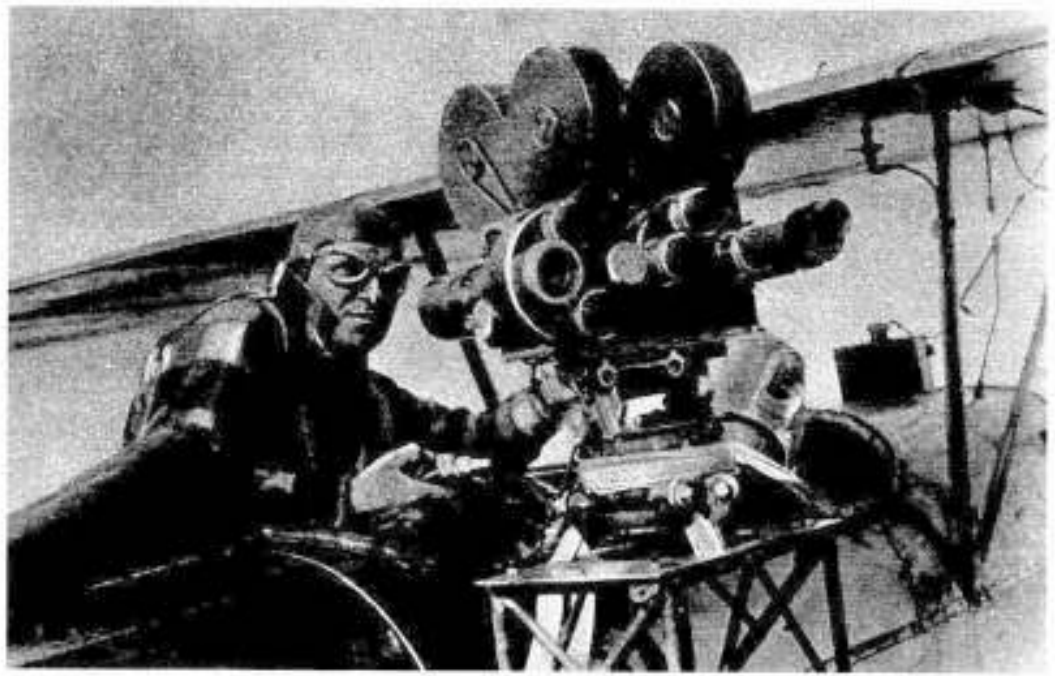

Det Arbeiter (Abb, 33 )

Julia Encke, Augenblicke der Gefahr : der Krieg und die Sinne (1914-1934), p. 88

7 Cette prise de contrôle exercée au nom de la guerre avec l'appui de la photographie et menée littérairement jusqu'à un ascendant revendiqué sur l'ensemble du domaine de la culture culmine chez Ernst Jünger. Par le biais de renvois ${ }^{11}$ entre recueils photographiques (1930-1933), souvenirs de guerre : In Stahlgewittern (Orages d'acier, 1929), 
essais spéculatifs : Der Arbeiter (Le Travailleur, 1931) et autres textes, il fait émerger pour sa part rien de moins qu'un nouvel homme qu'il voit sortir des tranchées et s'avancer au milieu de paysages bouleversés par des destructions gigantesques, dominés par des artefacts techniques mobiles, immenses et rapides, parcourus par des vivants à tout moment exposés à d'imprévisibles dangers. De cette image directement transposée de l'expérience du front il fait l'emblème du temps nouveau. L'expérience contemporaine est celle du danger et elle transforme le temps en un temps tissé d'instants dangereux (figures 2-4). Ceux qui sont revenus du front avaient appris des explosions qui surgissent de nulle part, de la musique des obus qui les précède, du silence dans lequel l'ennemi creuse des galeries souterraines, de l'absence d'odeur des gaz mortels ${ }^{12}$, que les dangers de la civilisation technique excèdent les capacités perceptives de l'humain, et qu'ils requièrent la "conscience froide " d'un appareillage lui-même technique dans lequel l'homme reçoit un nouveau visage qui à travers la disparition de la barbe, le raccourcissement de la chevelure, le développement des finalités protectrices du couvrechef, le raffinement du maquillage féminin, acquiert tous les traits d'un masque spécifique tendant vers le métal et l'artifice (Antlitz, figure 5). La " conscience froide » de l'homme appareillé n'est cependant pas seulement un accroissement des pouvoirs humains. Elle est aussi un accomplissement avec et dans la technique du «regard endurci » que les combattants se sont forgés au front. La précision tranchante et impitoyablement objectivante qu'ils ont appris à donner à leur regard dans les lunettes optiques qu'ils braquaient comme des fûts de fusils sur le champ de bataille, dont ils reconnaissent les pouvoirs dans l'appareil photographique, se veut en même temps une critique sans concession de toutes les déficiences de la société, inapte dans sa constitution présente à enregistrer tous les instants où se manifeste le danger. Un autre monde s'annonce dans la conjonction qu'Ernst Jünger s'emploie à réaliser entre la guerre et la culture : un monde où « la secrète disposition des organes artificiels des sens fait voir des espaces dans lesquels la destruction et la catastrophe jouent un grand rôle ", un monde qui nous conduit vers des situations « où une information, un avertissement, une menace doivent être parvenus à la conscience en quelques minutes", un monde dans lequel " derrière le caractère de divertissement des moyens totaux comme la radio ou les films se dissimulent des formes particulières de la discipline ${ }^{13}$; mais aussi bien une direction perçue en même temps que voulue du monde qui abrite un visible impensé quand on lit par exemple : «Dans l'espace politique le cinéma appartient aux armes dont on se sert avec la plus grande maîtrise (...). On le ressent très bien aux lieux où une autre substance cultuelle est encore vivante. À l'instant même où une ville comme La Mecque peut être photographiée, elle pénètre dans la sphère coloniale $»^{14}$.

\section{Intervalles dialectiques}

Des noeuds qui ainsi se nouaient à cette époque entre guerre et culture, Ernst Friedrich transmet quant à lui d'autres visages, d'autres «masques" revenus du front, en même temps qu'avec eux le forçage d'une autre pensée de la culture. C'est peut-être même avec plus d'effectivité que chez Ernst Jünger qu'un visage (Antlitz), plutôt qu'un paysage cerné par les dangers et les destructions, est véritablement donné à la guerre à savoir celui que donnent à voir les gueules cassées (figures 6-9). Sans doute, alors qu'elles sont présentes sur la couverture originale de l'ouvrage - on viendra à cette dernière -, disparaissent-elles de la réédition réalisée en 1980. Mais cette décennie est celle justement où Ernst Jünger 
réintègre la culture classique allemande (il reçoit le prix Goethe en 1982) et où il devient, invité par Helmut Kohl et François Mitterrand $(1993,1995)$, une pièce de prestige dans la réconciliation franco-allemande. C'est donc en vertu d'une véritable logique que les rééditions disponibles de Guerre à la guerre ! s'ornent en couverture d'un visage de la guerre rigoureusement jüngerien (figure 10). Une trace du dispositif mis en place par Ernst Friedrich néanmoins demeure. Car c'est aussi en raison de sa légende : "L'image de Dieu» avec masque à gaz (Das "Ebenbild Gottes" mit Gasmaske) que cette image est certainement venue en couverture. Et ce qui est mis sous les yeux est alors aussi tout autre. Non pas l'image d'une main mise sur la culture, déjà, par le «regard endurci » revenu du front et par la «conscience froide » qui l'accomplit techniquement au milieu du danger. Mais une tension entre l'image et le texte qui déchire la culture en direction d'une question. Or c'est l'installation et l'agencement de telles tensions au sein de l'archive issue de la première guerre mondiale, entre textes et images, images et images, textes et textes, qui occupent toute la tâche de Guerre à la guerre !. À la différence des caractères typographiques, qui, dans le discours préliminaire adressé « Aux peuples de toutes les nations ", se distinguaient afin d'éclairer le chemin à suivre pour les opérations de la pensée, les tensions dialectiques introduites dans l'archive de la guerre par une série d'opérations de composition de son matériau dressent à chaque page une aporie, qui requiert d'inventer et de frayer un chemin à la place de ceux que cette aporie a dérobés, et ici de le faire sous la contrainte d'affronter comme danger le danger de penser. Ernst Friedrich multiplie sous cette inspiration les heurts et les collisions entre les mots, les temps, les lieux, les conditions (figures 11-14). À l'aide de procédés communs avec l'ABC de la guerre (Kriegsfibel) composé lui aussi avec le plus grand soin par Bertolt Brecht et profondément étudié par Georges Didi-Huberman ${ }^{15}$, Guerre à la guerre ! d'Ernst Friedrich s'emploie à produire sur le modèle du collage et du photomontage une suite de chocs, d'« interruptions et de démembrements du continu», de «recadrages", d'« hétérogénéités calculées", dont la force épique contraint à chercher ce qui se tient derrière les événements. Cet art du montage, qui place Ernst Friedrich dans la modernité que Walter Benjamin déchiffrera dans Berlin Alexanderplatz d'Alfred Döblin ${ }^{16}$, ne s'enferme pas dans les oppositions immédiates, rhétoriques, directement issues de la propagande pacifiste. Il retrouve des procédés plus anciens tels que ceux dans lesquels G. DidiHuberman veut chez Brecht, à la suite de Walter Benjamin, reconnaitre l'épigramme, la subcriptio, l'allégorie ${ }^{17}$ (figure 15). Il charge en tous les cas les mots qui subsistent d'une teneur retrouvée de même qu'il rend aux figurations des corps détruits et abîmés ainsi que de la mort leur pouvoir de provoquer chez le lecteur une parole ou une pensée demeurées en attente (figures 16-19). Ernst Friedrich a essayé de réfléchir, à même son matériau et ses gestes de montage, ce qu'il produisait. Cette tentative occupe la couverture de l'édition originale du livre (figure 20). Il est difficile d'interpréter, à moins d'y consacrer des recherches plus étendues, quel atlas il avait exactement en vue. Ce dernier ne laisse pas d'être saisissant dans sa façon de faire revenir quelque fresque géométrisée de la Renaissance Italienne, et alors aussi d'attirer l'attention, pour finir, sur un autre dispositif qui court à travers tout le livre. Celui-là, en effet, chacun le voit, est rédigé en quatre langues : l'allemand, le français, l'anglais, le néerlandais. La répétition des textes que cette contrainte induit ne se contente pas simplement d'élargir le public qu'Ernst Friedrich veut intéresser à son travail. Elle ne porte pas seulement témoignage, jusque dans les défauts des traductions, de l'existence d'une communauté transnationale qui autour d'Ernst Friedrich hantait les lieux et les activités de l'Anti-Kriegs Museum. Par une subscriptio généralisée qui lui est propre elle surimprime à chaque texte, à chaque 
image, à chaque dispositif créé par le montage, et par là elle relance en eux, la question même de l'intervalle qui sépare ces langues et les peuples qui les parlent. Les écarts en provenance des maladresses de traduction ne rendent que plus sensible la métamorphose du conflit armé qui demeure à réaliser dans la culture vers laquelle l'ouvrage fait signe.

\section{Figure 6}

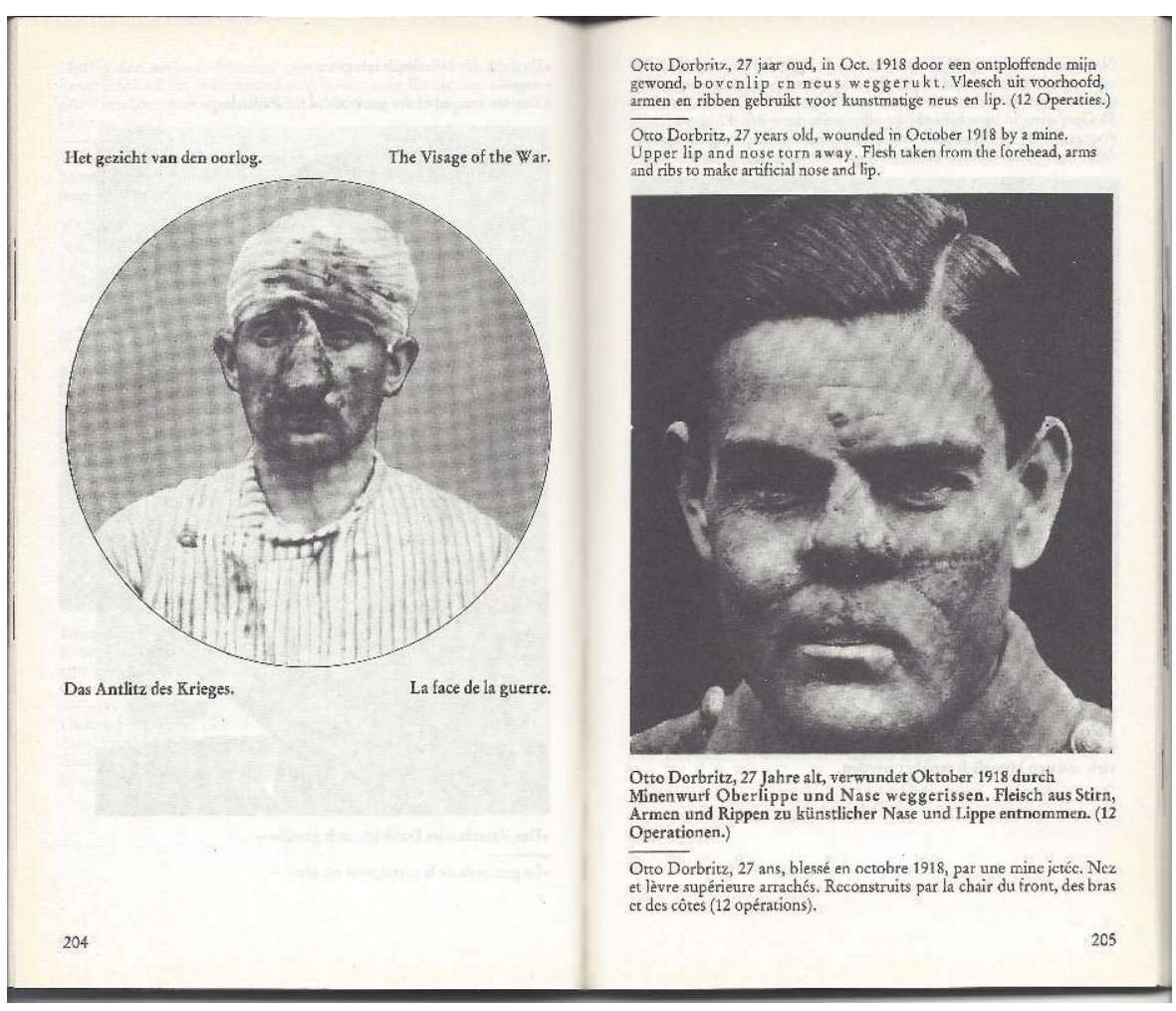

Ernst Friedrich, Krieg dem Kriege! Guerre à la guerre! War against war! Oorlog aan den Oorlog, pp. 204-5 
Figure 7

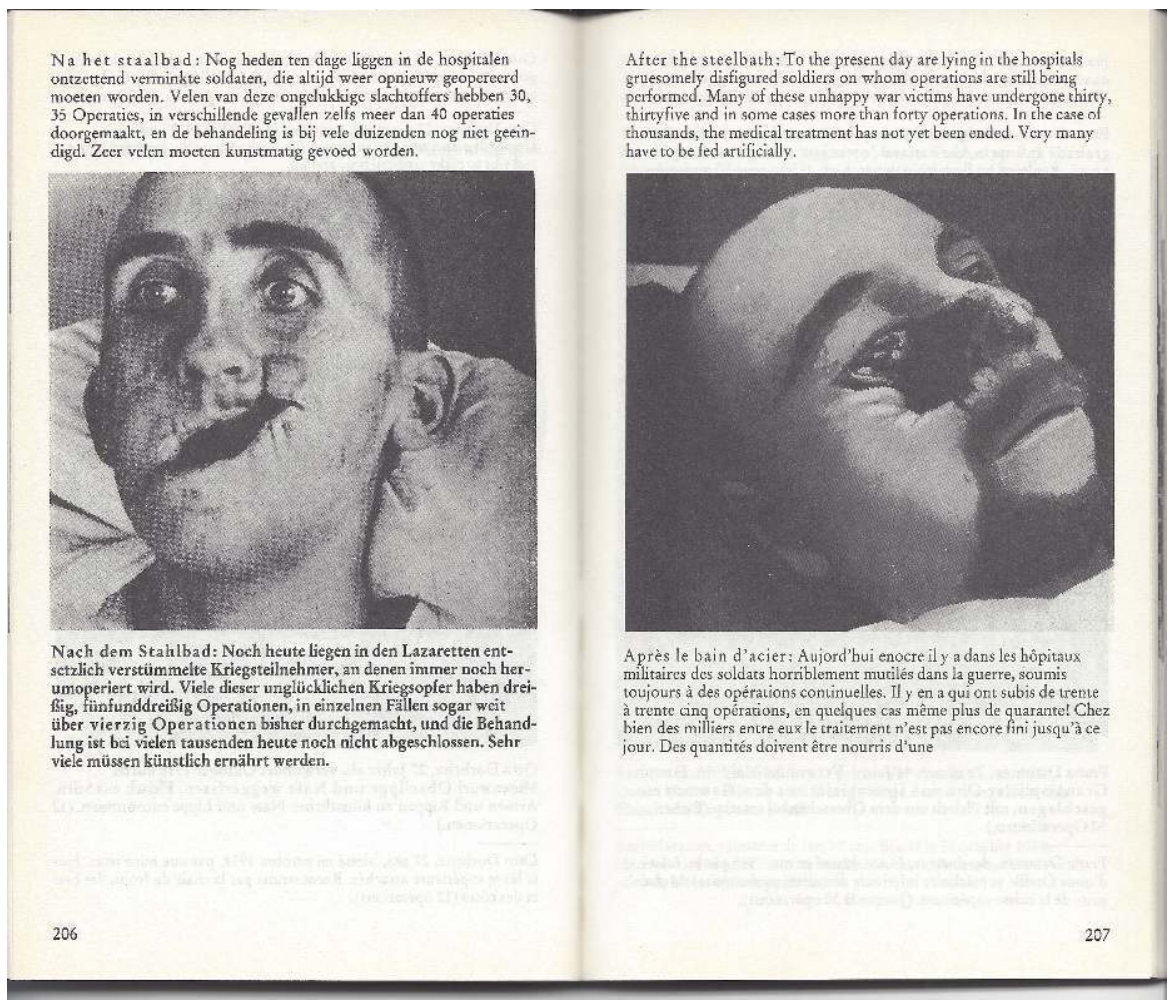

Ernst Friedrich, Krieg dem Kriege! Guerre à la guerre! War against war! Oorlog aan den Oorlog, pp. 206-7

Figure 8

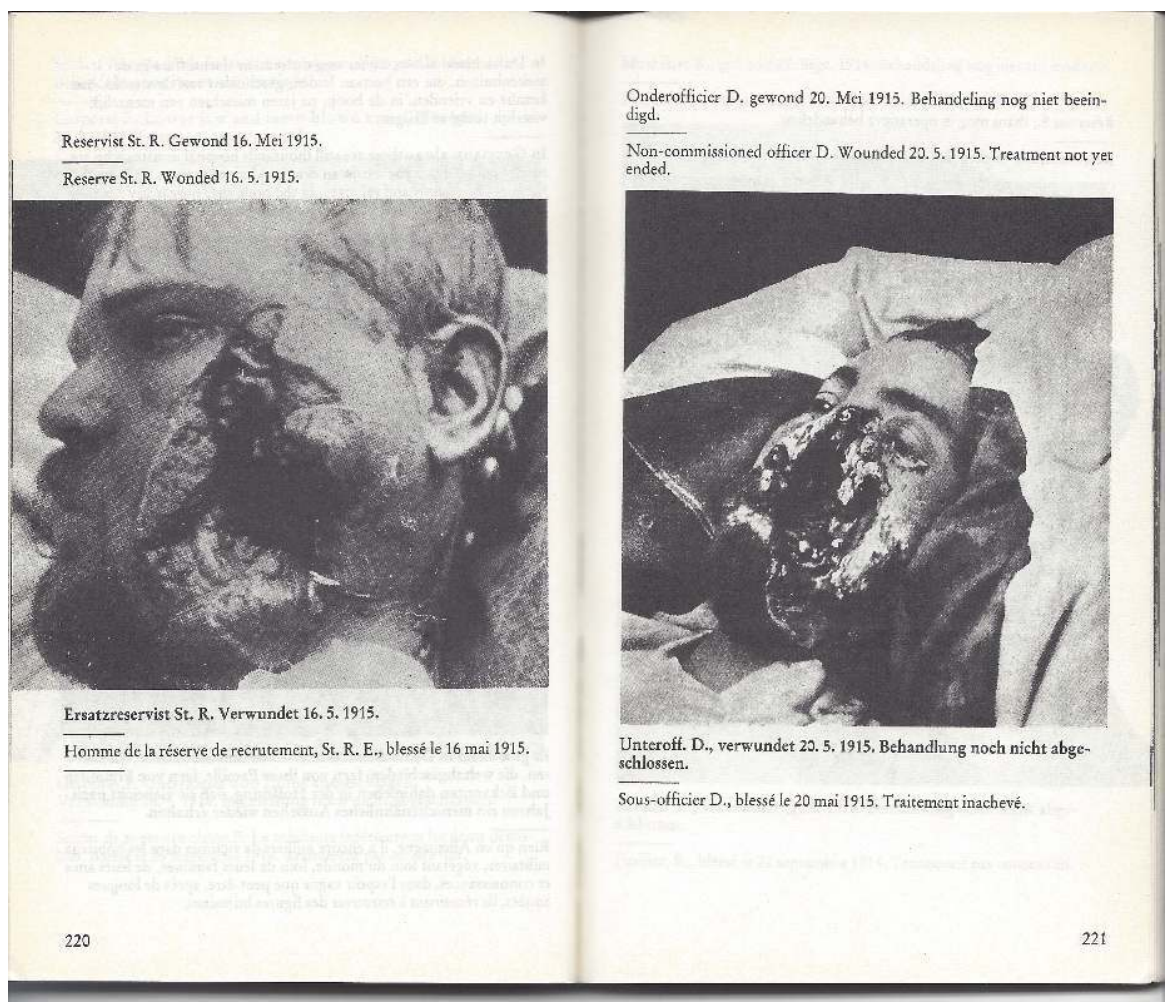

Ernst Friedrich, Krieg dem Kriege! Guerre à la guerre! War against war! Oorlog aan den Oorlog, pp. 220-1 
Figure 9

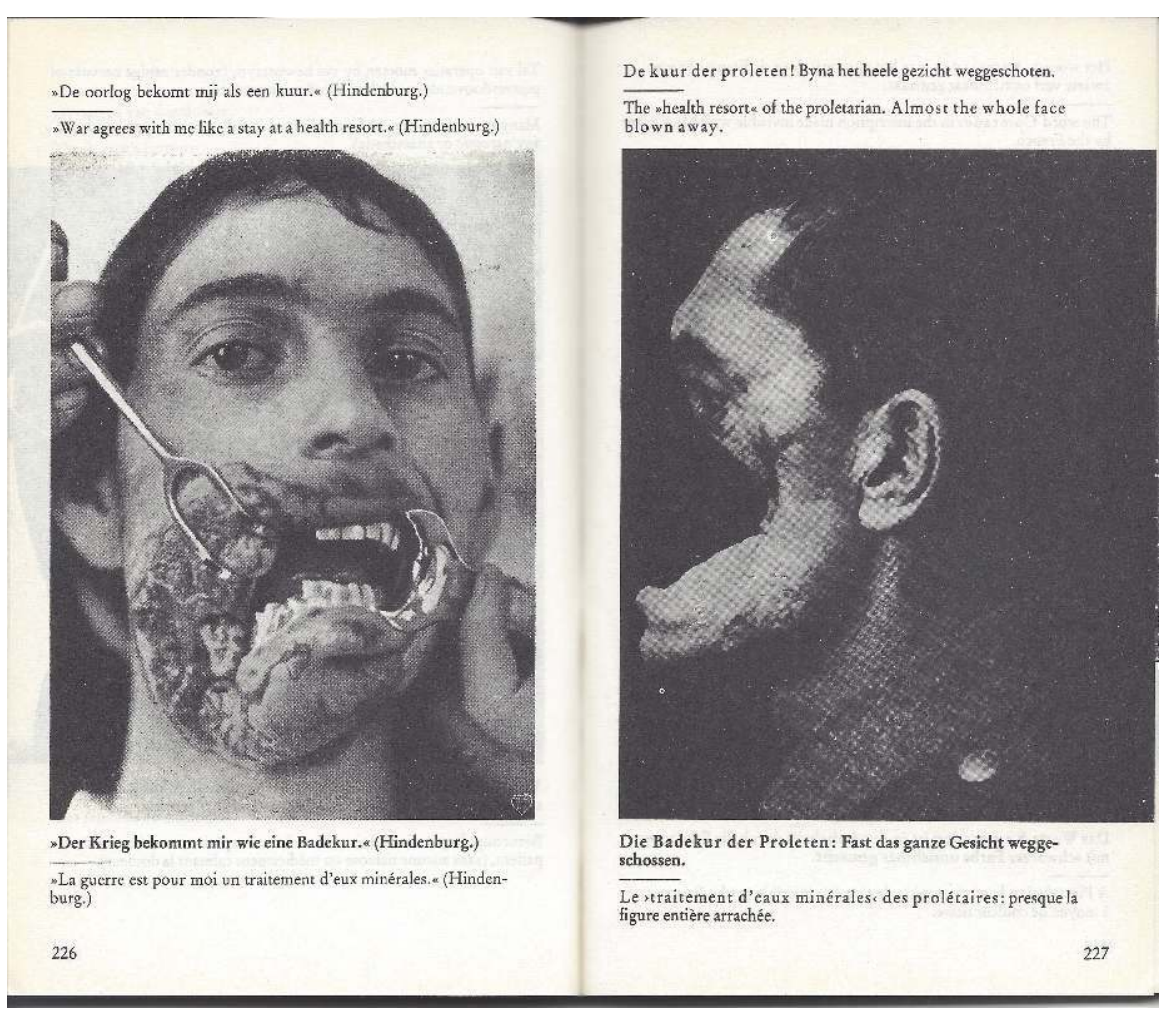

Ernst Friedrich, Krieg dem Kriege! Guerre à la guerre! War against war! Oorlog aan den Oorlog, pp. 226-7

Figure 10

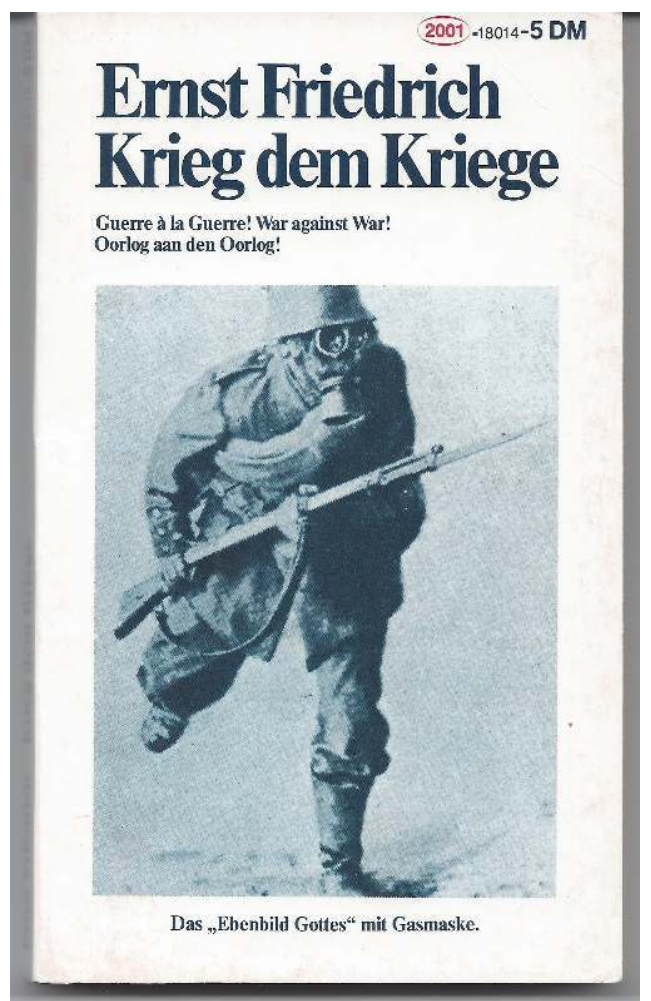

Ernst Friedrich, Krieg dem Kriege! Guerre à la guerre! War against war! Oorlog aan den Oorlog (couverture) 
Figure 11

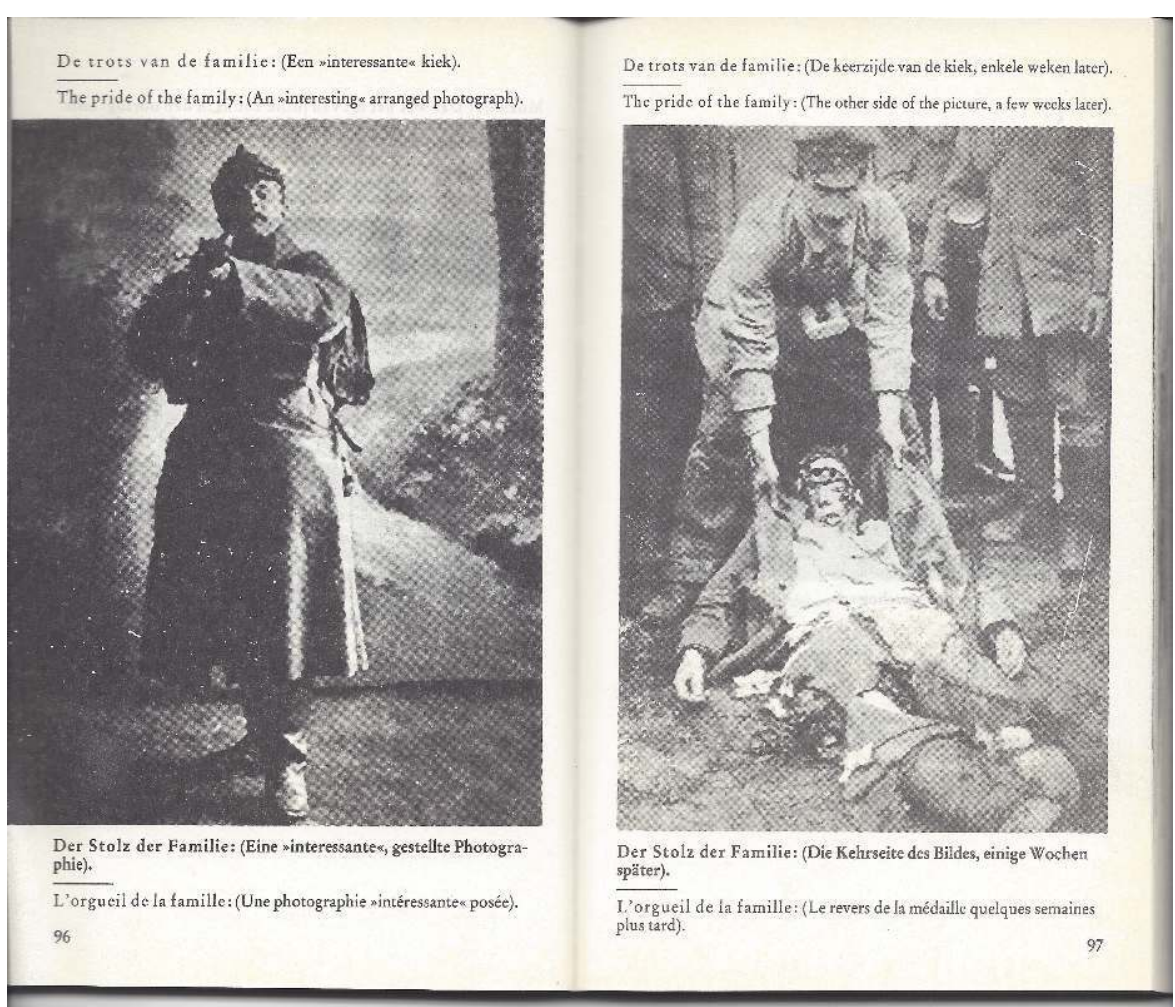

Ernst Friedrich, Krieg dem Kriege! Guerre à la guerre! War against war! Oorlog aan den Oorlog, pp. 96-7

Figure 12

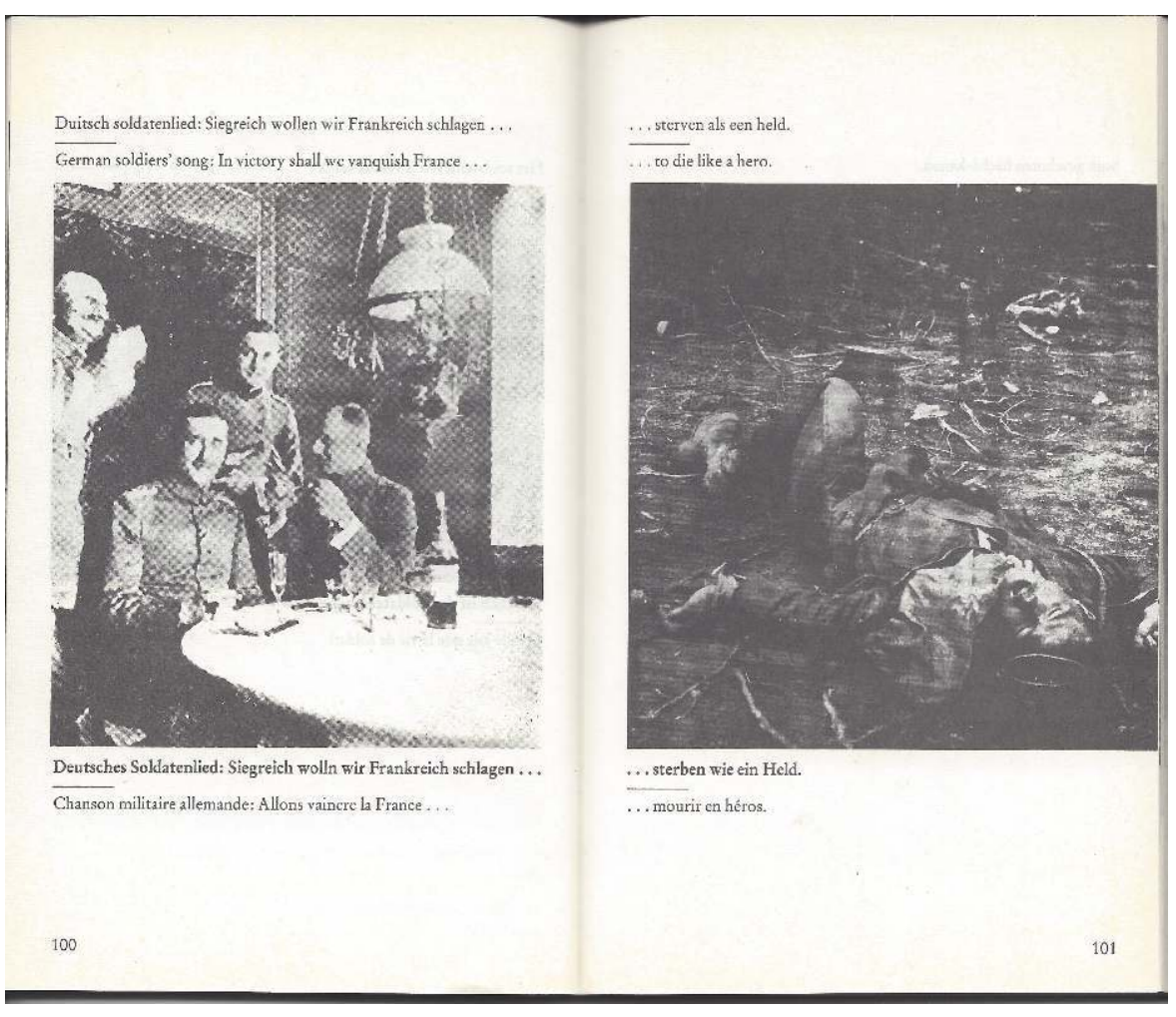

Ernst Friedrich, Krieg dem Kriege! Guerre à la guerre! War against war! Oorlog aan den Oorlog, pp. 100-1 
Figure 13

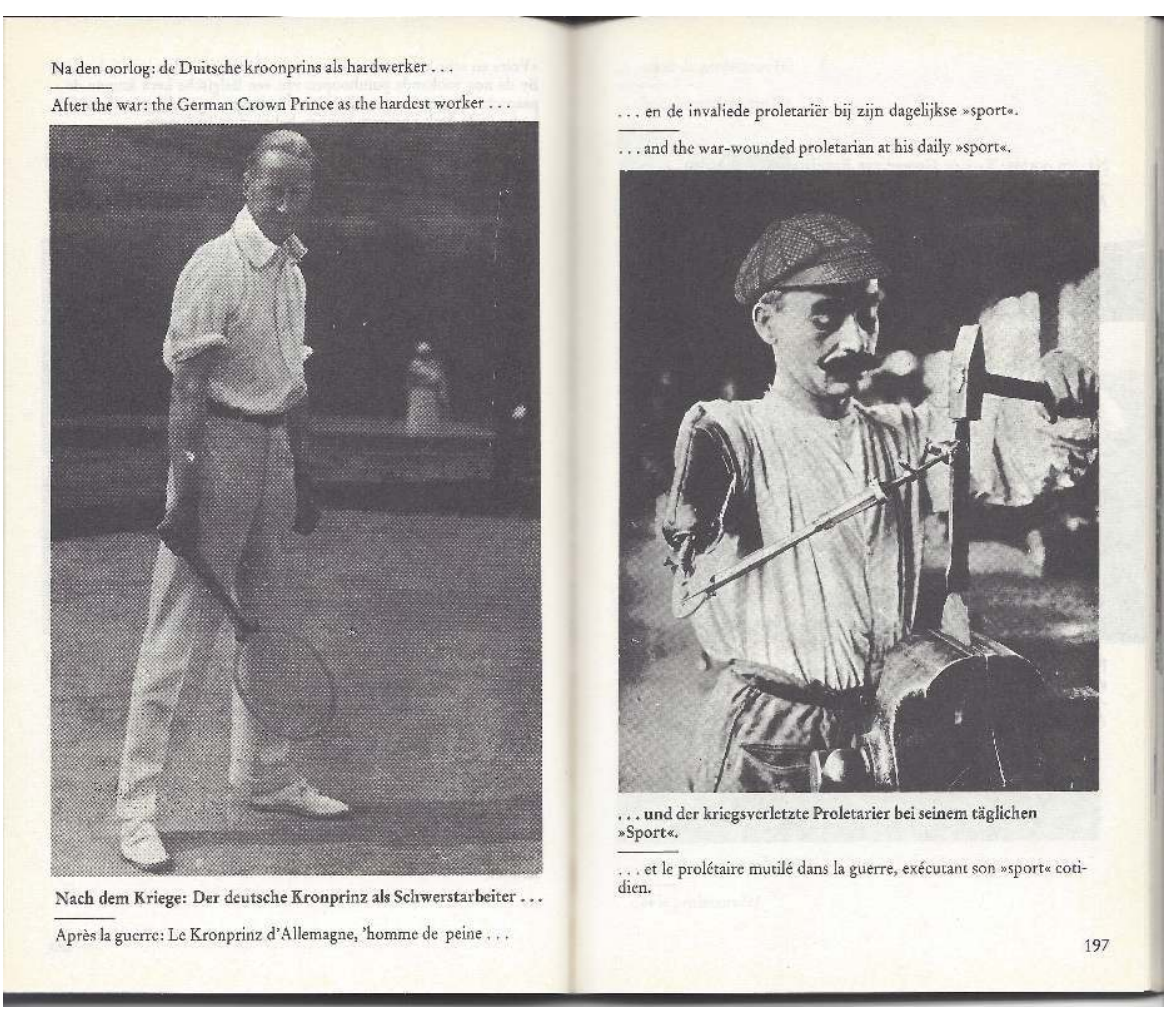

Ernst Friedrich, Krieg dem Kriege! Guerre à la guerre! War against war! Oorlog aan den Oorlog, pp. 196-7

Figure 14

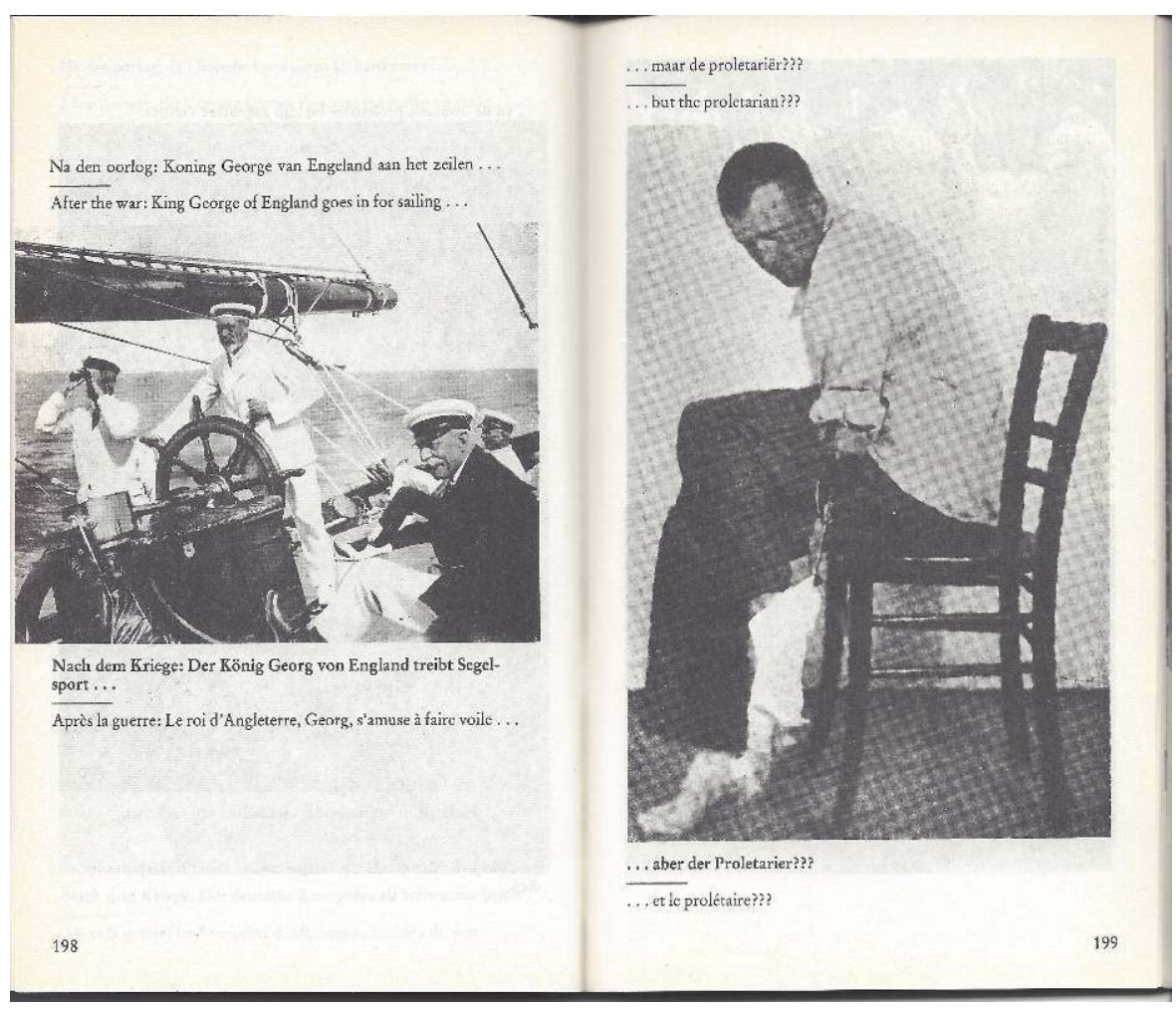

Ernst Friedrich, Krieg dem Kriege! Guerre à la guerre! War against war! Oorlog aan den Oorlog, pp. 198-9 
Figure 15

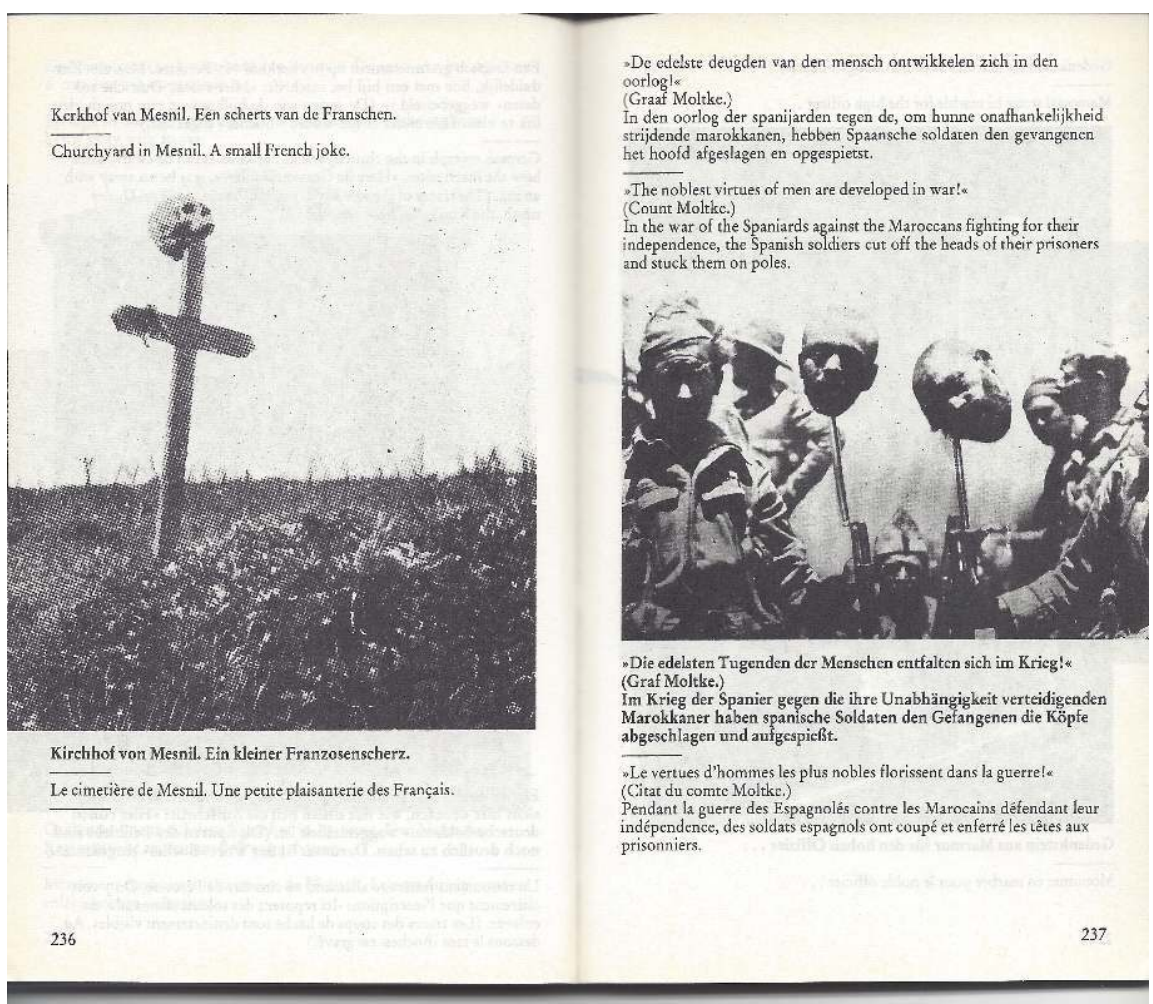

Ernst Friedrich, Krieg dem Kriege! Guerre à la guerre! War against war! Oorlog aan den Oorlog, pp. 236-7

\section{Figure 16}

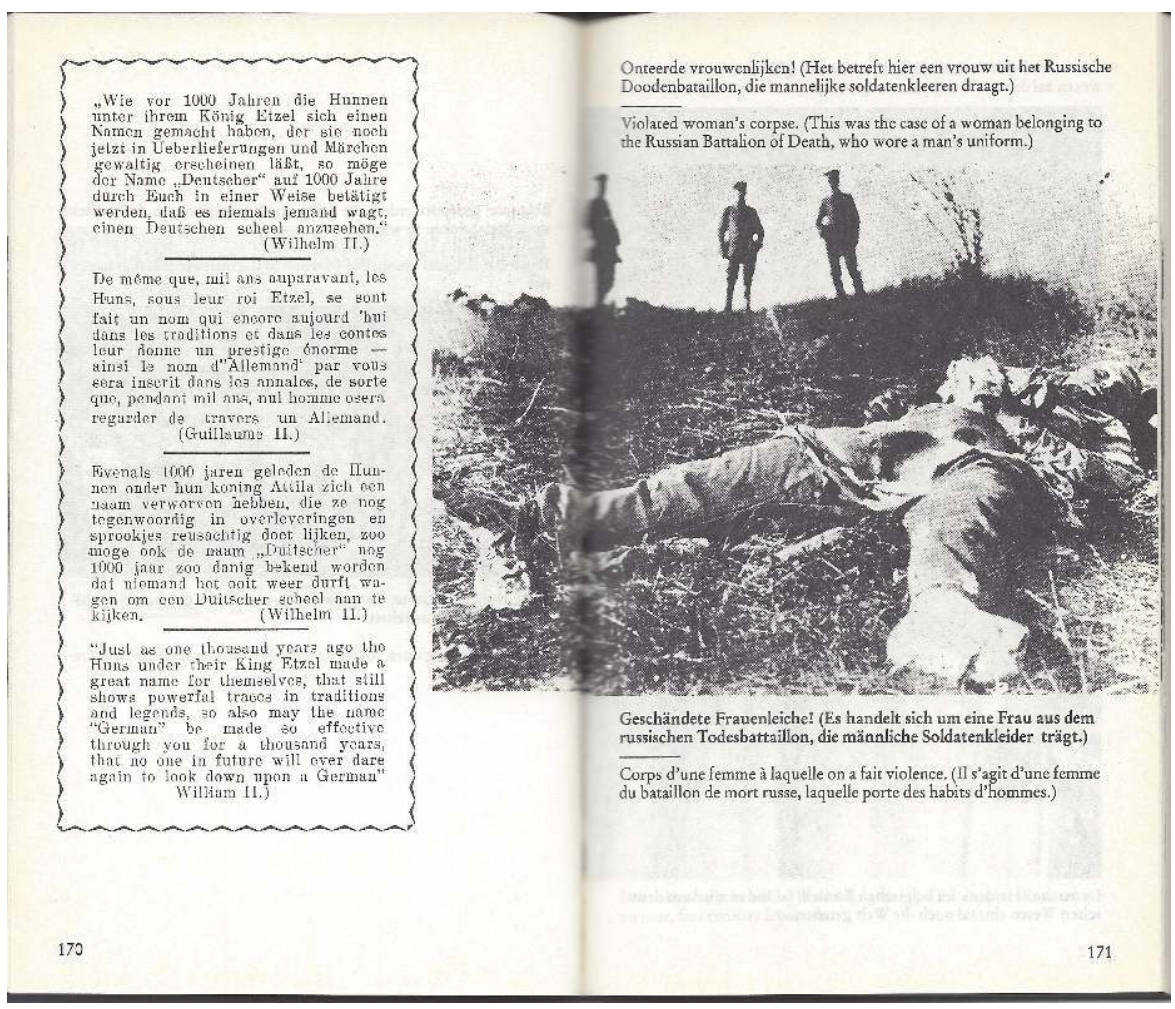

Ernst Friedrich, Krieg dem Kriege! Guerre à la guerre! War against war! Oorlog aan den Oorlog, pp. 170-1 
Figure 17

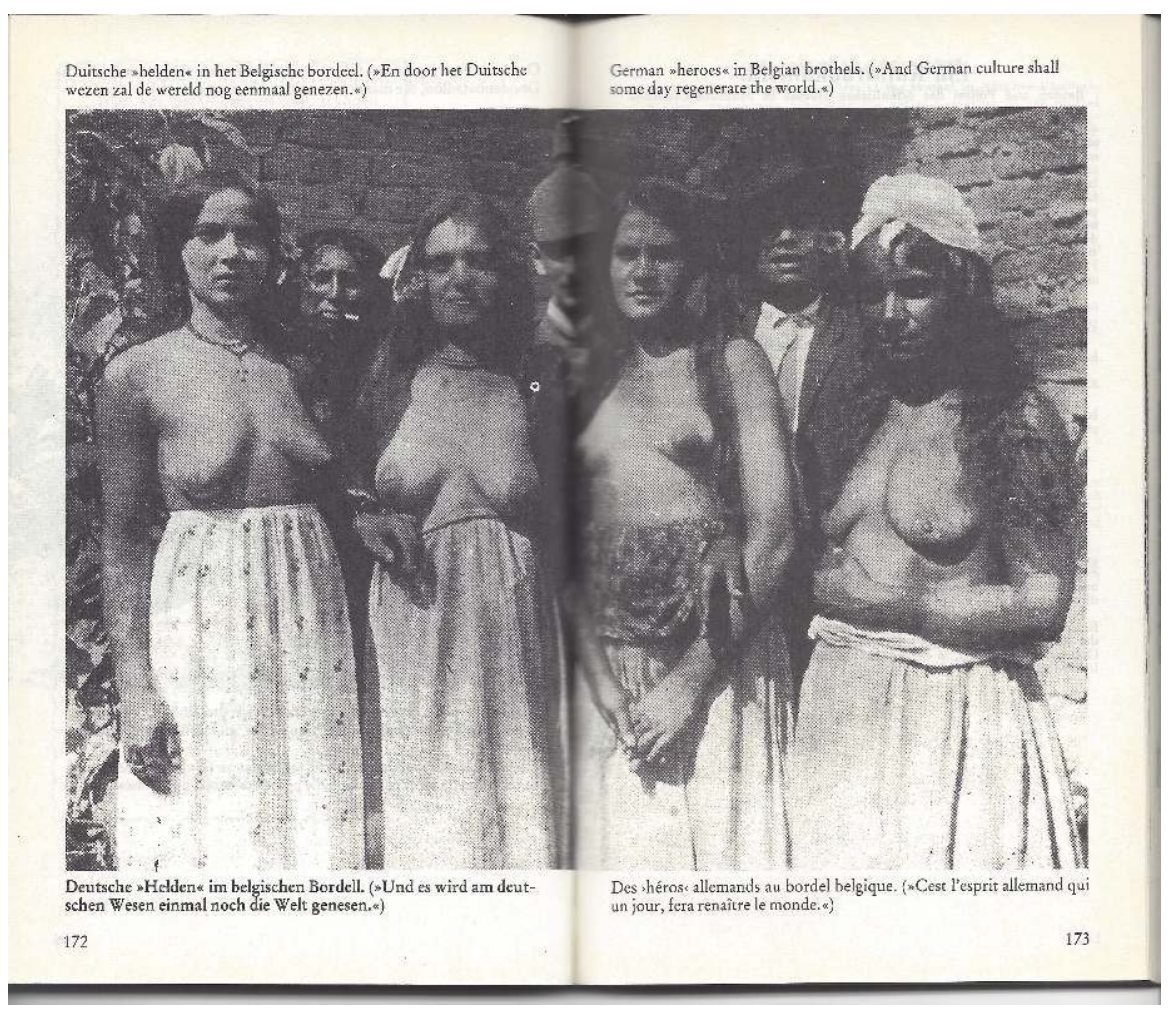

Ernst Friedrich, Krieg dem Kriege! Guerre à la guerre! War against war! Oorlog aan den Oorlog, pp. 172-3

\section{Figure 18}

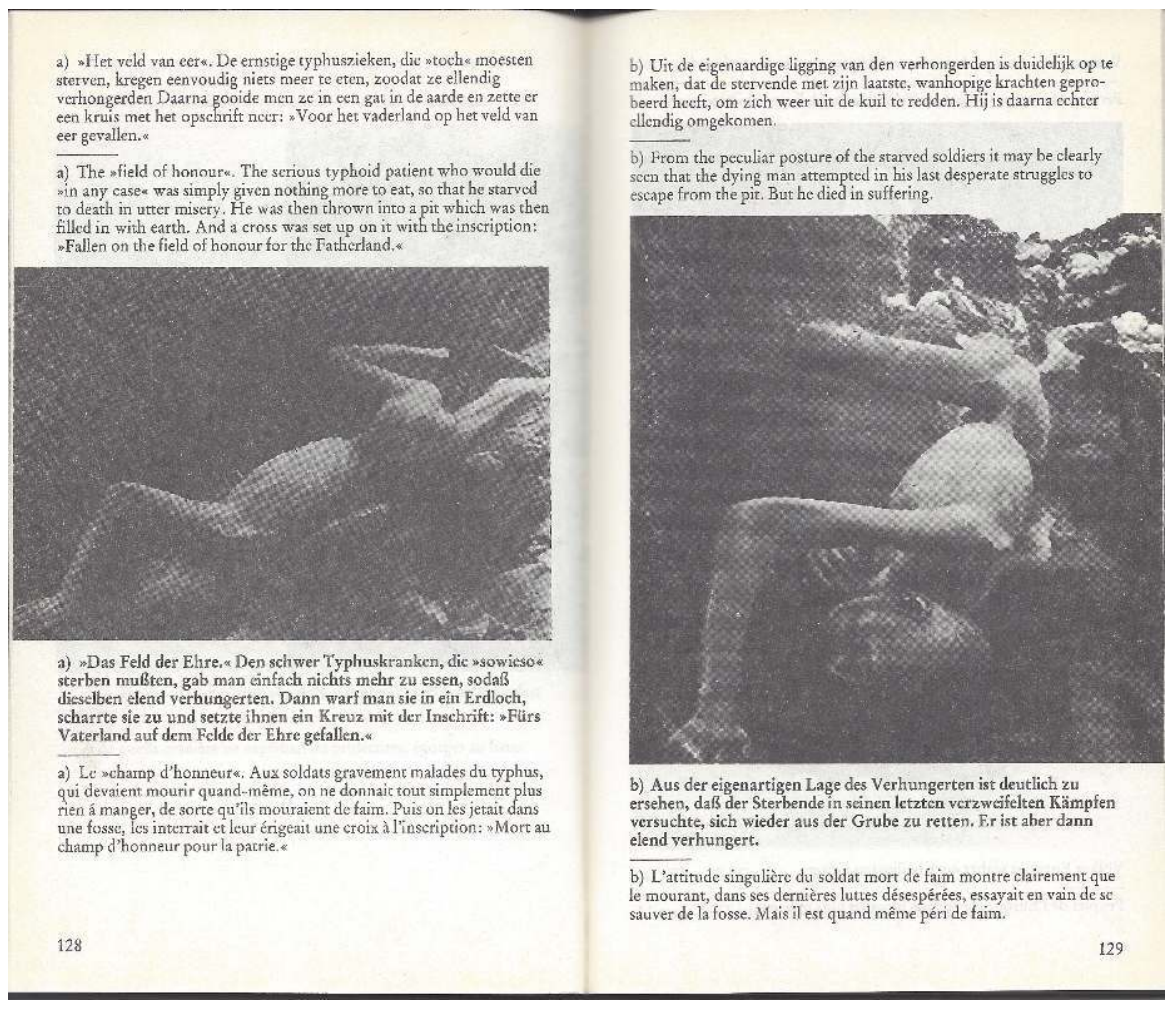

Ernst Friedrich, Krieg dem Kriege! Guerre à la guerre! War against war! Oorlog aan den Oorlog, pp. 128-9 
Figure 19

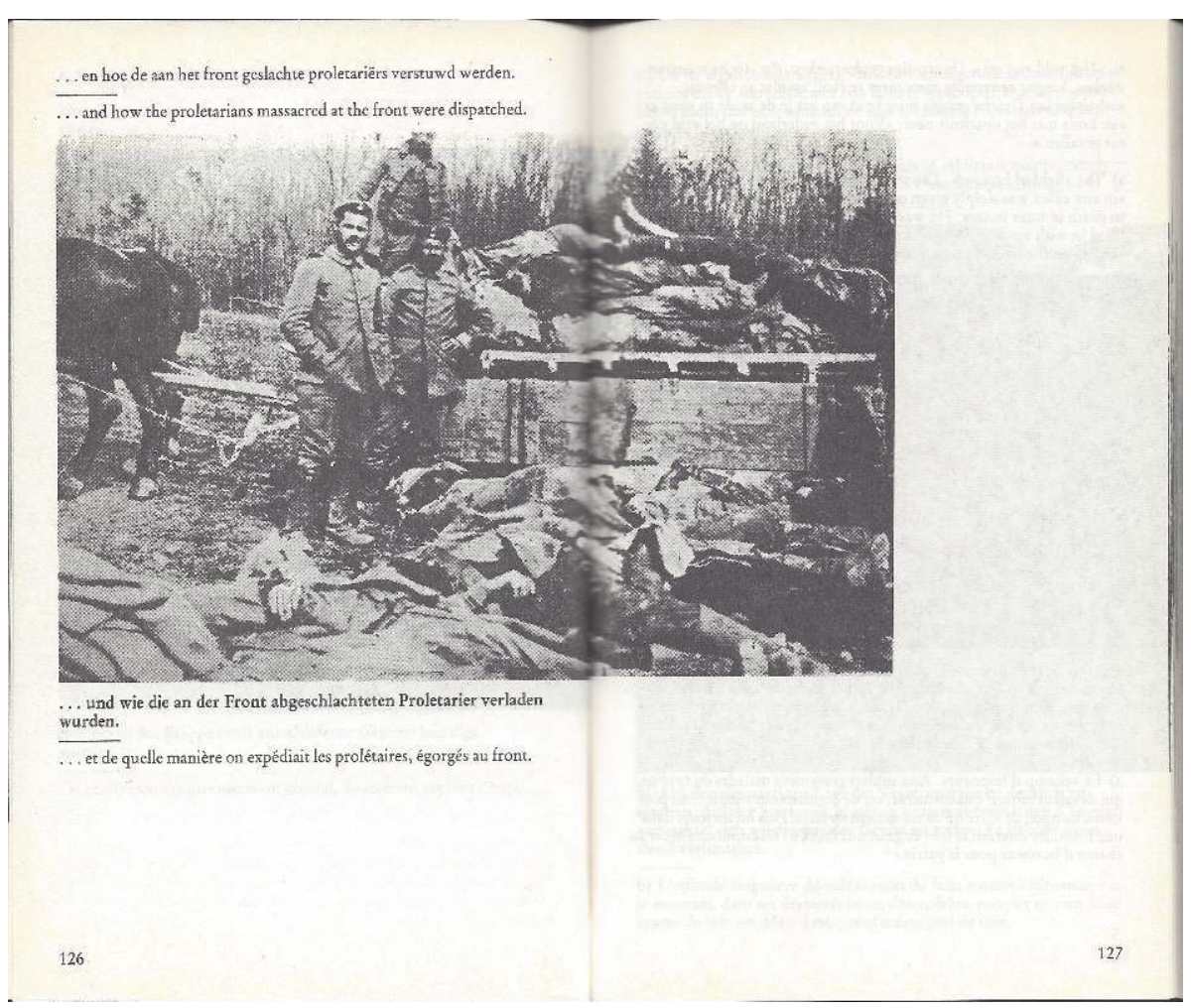

Ernst Friedrich, Krieg dem Kriege! Guerre à la guerre! War against war! Oorlog aan den Oorlog, pp. 126-7

\section{Figure 20}

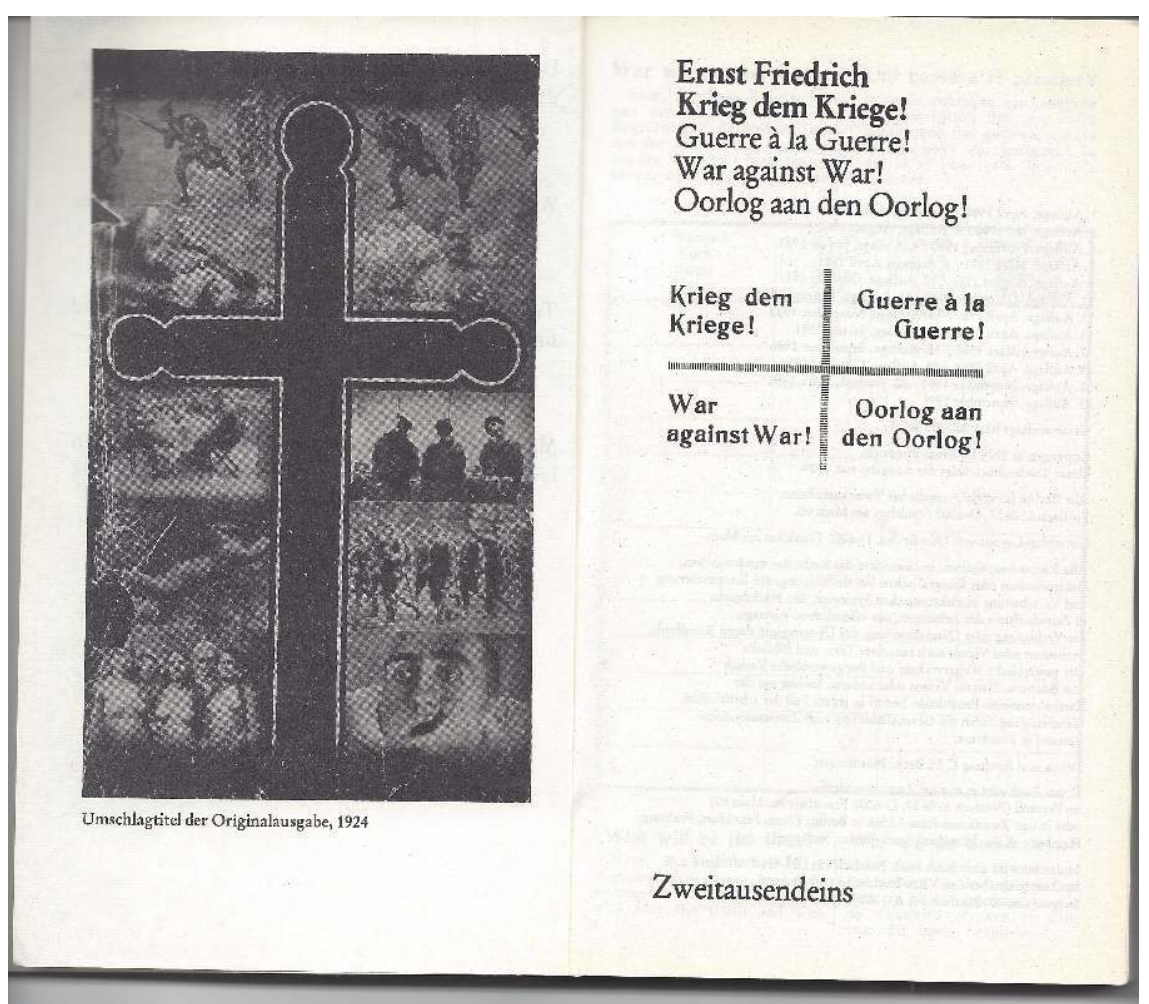

Ernst Friedrich, Krieg dem Kriege! Guerre à la guerre! War against war! Oorlog aan den Oorlog, p. 2 


\section{L'Europe et les moyens purs}

nitiatives lancées par Ernst Friedrich ne sont pas entièrement éteintes mais presque. Tout autant que l'« anarchie » revendiquée par Ernst Jünger, elles ont, elles aussi, été rattrapées par la réconciliation européenne. Les formes qu'elles ont fini par prendre se sont détachées de l'intrigue qu'elles avaient su nouer, comme dans ces films où sur l'écran final vient s'afficher ce que les personnages, rentrés dans la vie, sont devenus séparément quelques années plus tard.

Après avoir rejoint la Résistance française dans un maquis de Lozère, avoir été blessé deux fois, participé à la libération de Nîmes et d'Alès, Ernst Friedrich a ainsi acquis la nationalité française et a adhéré à la SFIO (Section française de l'Internationale ouvrière). Avec quelques fonds il réussira à acquérir en région parisienne, d'abord une vieille péniche, puis un terrain sur une île où il fera construire un centre de jeunesse international de 50 lits auquel il donnera le nom d'« île de la paix ». Après avoir rempli son office d'être un lieu d'accueil et de rencontre pour de jeunes ouvriers ce centre sera vendu ainsi que détruit à sa mort en 1962.

11 De son côté l'Anti-Kriegs Museum qu'Ernst Friedrich n'avait pas réussi à faire renaître réouvrira à Berlin en 1982 et continue aujourd'hui de présenter des objets et documents sur la guerre comme n'importe quel musée spécialisé. Il s'est adjoint une Peace Gallery qui défend l'idée que les scènes de mort, de destruction et de violence figurent dans l'histoire des arts depuis les origines et qu'il demeure important d'accueillir librement sur ce thème des expositions et installations d'artistes $d u$ monde entier ainsi que des conférences sur les grands penseurs pacifistes.

12 Le livre Guerre à la guerre! circule entre les mains des collectionneurs, et, malgré ses rééditions en tirages limités, est généralement épuisé. Il est entré dans les dictionnaires de la pensée anarchiste. Les photographies qu'il contient sont citées dans les études savantes qui approfondissent les transformations de la sensibilité en Europe pendant l'entre-deux guerres. Les intervalles dialectiques qu'il avait su inventer n'opèrent plus beaucoup. Les écarts entre les langues et les peuples qu'ils avaient considérés sont pris en charge par de nouvelles institutions de la jeunesse européenne et tournent le dos aux visages de la guerre.

13 Ce qui frappe dans ces devenirs est la façon dont ils témoignent de la bonne volonté européenne. L'Europe continue de développer au sein de sa culture plusieurs des moyens tels que le dialogue et l'entente cordiale que l'écrit de jeunesse de Walter Benjamin Critique de la violence avait regroupés sous la catégorie de "moyens purs». Elle en fait presque sa spécialité sans avoir beaucoup pensé aux métamorphoses civiles de la violence qu'elle contient et dont l'essai de Benjamin faisait pour sa part une question cruciale, ni sans avoir beaucoup réfléchi à l'étrange limitation qui l'avait centrée sur son périmètre le plus étroit - chez Ernst Friedrich : l'allemand, le français, l'anglais, le néerlandais - au sortir d'une grande guerre qui avait pourtant été réellement mondiale. Non seulement cette limitation l'avait assez peu préparée aux guerres de libération coloniale qui suivirent peu après, mais encore elle vide de sens et généralement de réalité les îles de paix et Peace Galleries par lesquelles elle continue de développer des moyens "pacifiques» de la politique à l'abri de frontières toujours plus impitoyablement verrouillées sur une prospérité plus sinistre que véritablement en crise. À Ernst Jünger et

Anthropology \& Materialism, 3 | 2016 
aux auteurs de Guerre et guerriers Walter Benjamin avait, dans les années 1930, objecté que la guerre dont ils voulaient faire entrer l'expérience dans la culture afin qu'elle y déploie des conséquences essentielles n'était qu'une adaptation de la guerre « universelle » et « dernière » taillée sur mesure pour célébrer un « culte de la guerre, alors même qu'il n'y avait plus de véritable ennemi $»^{18}$, et pour «embraser l'horizon» avec des discours d'entrepreneurs spécialisés qui ne s'étaient jamais réellement "heurtés à la paix »" L'Europe que nous connaissons et qui a accueilli Ernst Jünger dans l'entourage de ses plus grands dirigeants organise pour sa part avec soin les nombreuses versions du spectacle qu'elle donne d'une paix "universelle» et «dernière». Ce qui noue les deux est certainement l'étroitesse de l'horizon. C'est, avec les images d'immigrés et de clandestins qui se détruisent pour venir en Europe, avec les images de ceux encore qui se détruisent de ne pas y venir, que la culture contemporaine compose les pages d'un Guerre à cette paix. La philosophie contemporaine se mesure d'une façon essentielle à sa capacité de maintenir, sous des formes multiples, inventives et articulées à la saisie d'une situation, de telles guerres.

\section{BIBLIOGRAPHIE}

Benjamin Walter, 2000, CEuvres II, Paris, Gallimard

Didi-Huberman Georges, 2011, Quand les images prennent position. L'oeil de l'histoire, 1, Paris, Minuit Encke Julia, 2006, Augenblicke der Gefahr : der Krieg und die Sinne (1914-1934), München, Eugen Fink, Friedrich Ernst, 1980, Krieg dem Kriege! Guerre à la guerre! War against war ! Oorlog aan den Oorlog (1924), Frankfurt, Zweitausendeins

Jünger Ernst (Hrsg.), 1930, Das Antlitz des Weltkrieges - Fronterlebnisse deutsche Soldaten, Berlin, Neufeld \& Henius

Jünger Ernst (Hrsg.), 1928, Luftfahr ist not !, Leipzig und Nürnberg, Protektorat des Deutschen Luftfahrtverbandes

Jünger Ernst, 1934, Blätter und Steine, Halbleinen, Hanseatische Verlagsanstalt Hamburg

Jünger Ernst, 1932, Der Arbeiter. Herrschaft und Gestalt, Hamburg, Hanseatische Verlagsanstalt Junior Richard \& Ernst Jünger, 1931, Hier spricht der Feind - Kriegserlebnisse unserer Gegner, Berlin, Neufeld \& Henius

Rancière Jacques, 1987, Le maître ignorant. Cinq leçons sur l'émancipation intellectuelle, Paris, Fayard (rééd. Paris, 10/18 Poche, 2004)

Rex Hermann, 1926, Der Weltkrieg in seiner rauhen Wirklichkeit, Oberammergau, Hermann Rutz Verlag

Schauwecker Franz, 1928, So war der Krieg - 200 Kampfaufnahmen aus der Front, Berlin, Frunsberg Verlag

Schultz Edmund \& Jünger Ernst, 1933, Die veränderte Welt - Eine Bilderfibel unserer Zeit, Breslau, Korn 
Soldan Georg, 1926, Geleitworte, Der Weltkrieg im Bild. Originalaufnahmen des Kriegs-Bild- und Filmamtes aus der modernen Materialschlacht, Berlin, Verlag « Der Weltkrieg im Bild »

Werneburg Brigitte, 1995, « Der Arbeiter und sein Bilderbuch. Der Wechsel des Mediums in Ernst Jüngers Fotobüchern » [URL : http://werneburg.nikha.org/home.php?id=499]

\section{NOTES}

1. Walter Benjamin «Théories du fascisme allemand. À propos de l'ouvrage collectif Guerre et Guerriers publié sous la direction d'Ernst Jünger », 1ère publication dans Die Gesellschaft, n7, 1930, tr. fr. dans Oeuvres, II, Paris, Gallimard, 2000, p. 215.

2. Ernst Friedrich, Krieg dem Kriege! Guerre à la guerre! War against war ! Oorlog aan den Oorlog (1924), Frankfurt, Zweitausendeins, 1980.

3. Walter Benjamin, op. cit., p. 204.

4. Sur cette catégorie se reporter aux livres de J. Rancière. Voir par exemple: «L'homme est un animal politique parce qu'il est un animal littéraire qui se laisse détourner de sa destination "naturelle" par le pouvoir des mots » (Jacques Rancière, Le partage du sensible, Paris : La Fabrique, 2000, p. 63).

5. Walter Benjamin, "La crise du roman. À propos de Berlin Alexanderplatz de Döblin ", 1ère publication dans Die Gesellschaft, $n^{\circ} 7,1930$, tr. fr. dans Oeuvres, II, Paris, Gallimard, p. 197.

6. Voir le site Internet de l'Anti-Kriegs Museum : http://anti-kriegs-museum.de/

7. Julia Encke, Augenblicke der Gefahr : der Krieg und die Sinne (1914-1934), München, Eugen Fink, 2006.

8. Julia Encke cite dans cette veine: Hermann Rex, Der Weltkrieg in seiner rauhen Wirklichkeit, Oberammergau, Hermann Rutz Verlag, 1926; Georg Soldan, Geleitworte, Der Weltkrieg im Bild. Originalaufnahmen des Kriegs-Bild- und Filmamtes aus der modernen Materialschlacht, Berlin, Verlag «Der Weltkrieg im Bild», 1926 ; Franz Schauwecker, So war der Krieg - 200 Kampfaufnahmen aus der Front, Berlin, Frunsberg Verlag, 1928.

9. Voir Jacques Rancière, Le maître ignorant. Cinq leçons sur l'émancipation intellectuelle, Paris, Fayard, 1987 (rééd. Paris, 10/18 Poche, 2004)

10. Ernst Jünger (Hrsg.), Luftfahr ist not!, Leipzig und Nürnberg, Protektorat des Deutschen Luftfahrtverbandes, 1928 ; Das Antlitz des Weltkrieges - Fronterlebnisse deutsche Soldaten, Berlin, Neufeld \& Henius, 1930 ; Hier spricht der Feind - Kriegserlebnisse unserer Gegner. Mit einer Einleitung von Ernst Jünger, Herausgegeben von Richard Junior, Berlin, Neufeld \& Henius, 1931 ; Edmund Schultz \& Ernst Jünger Die veränderte Welt - Eine Bilderfibel unserer Zeit, Breslau, Korn, 1933.

11. Se reporter notamment à Brigitte Werneburg, "Der Arbeiter und sein Bilderbuch. Der Wechsel des Mediums in Ernst Jüngers Fotobüchern » (1995) [URL : http://werneburg.nikha.org/ home.php?id=499]

12. Voir Julia Encke, op. cit.

13. Ernst Jünger, "Über den Schmerz» dans Blätter und Steine, Halbleinen, Hanseatische Verlagsanstalt Hamburg, 1934, p. 202, cité par Brigitte Werneburg, op. cit.

14. Ernst Jünger, Der Arbeiter. Herrschaft und Gestalt (1932), cité par Brigitte Werneburg, op. cit.

15. Georges Didi-Huberman, Quand les images prennent position. L'oeil de l'histoire, 1, Paris, Minuit, 2011.

16. Walter Benjamin, « La crise du roman » (1930), dans CEuvres II, pp. 192-3.

17. Georges Didi-Huberman, op. cit., pp. 153-5

18. Walter Benjamin, «Théories du fascisme allemand », dans CEuvres II, p. 205.

19. Ibid. p. 209 


\section{AUTEUR}

\section{STÉPHANE DOUAILLER}

Professeur de Philosophie à l'Université Paris 8 Vincennes Saint-Denis, Laboratoire d'études et de recherches sur les logiques contemporaines de la philosophie (LLCP EA 4008) 